\title{
Oesophageal atresia and tracheo-oesophageal fistula
}

\author{
A Goyal, M O Jones, J M Couriel, P D Losty
}

Arch Dis Child Fetal Neonatal Ed 2006;91:F381-F384. doi: 10.1136/adc.2005.086157

Oesophageal atresia-tracheo-oesophageal fistula has featured in paediatric surgery since its beginnings. The first successful primary repair was in 1941 . With overall survival now exceeding $90 \%$ in dedicated centres, the emphasis has changed to reducing morbidity and achieving improvements in the quality of life. An overview of current and emerging strategies in managing patients with this condition is presented. Advances in developmental biology and molecular genetics reflecting improved understanding of the pathogenesis are highlighted.

See end of article for authors' affiliations ......................

Correspondence to: Professor Losty, Institute of Child Health, Royal Liverpool Children's Hospital (Alder Hey), Eaton Road, Liverpool L12 2AP, UK; paul.losty@liv. ac.uk

Accepted

15 November 2005
O esophageal atresia (OA) and tracheooesophageal fistula (TOF) has been a key domain of paediatric surgery since its early beginnings and continues to challenge specialists who care for these vulnerable children. The first successful primary repair by Cameron Haight, an American surgeon, in 1941 represented a landmark for a young surgical specialty. ${ }^{1}$ Reports from the United Kingdom soon followed with notable successes recorded by Franklin (1947) at the Hammersmith Hospital London, Sir Denis Browne (1948) at Great Ormond Street, and Peter Paul Rickham (1949) in Liverpool. ${ }^{2}$ With overall survival now exceeding $90 \%$ in dedicated centres, ${ }^{3}$ emphasis in the modern era has been on reducing morbidity and achieving improvements in the quality of life. An overview of current and emerging strategies in managing patients with OA-TOF is presented. Advances in developmental biology and molecular genetics reflecting improved understanding of the pathogenesis are highlighted.

\section{BACKGROUND}

OA embraces a spectrum of anomalies with OA and distal TOF being the most common defect $(86 \%)$. Important variants include isolated "pure" OA without fistula (7\%) and the rare $\mathrm{H}$ type TOF without atresia (4\%). ${ }^{4}$ With an estimated incidence of 1 in 3000 births, it represents one of the common congenital malformations seen in major paediatric surgical centres. The baby with OA-TOF classically presents with respiratory distress and feeding difficulties, choking, and frothing in the first few hours of life. Antenatal diagnosis may be suspected from maternal polyhydramnios and absence of the fetal stomach bubble. In one study, the sensitivity of antenatal scans diagnosing OA was estimated to be $42 \%$ with a positive predictive value of $56 \% .^{5}$ Karyotyping should be conducted if a prenatal diagnosis of OA is suspected because of the high reported incidence of trisomy 18 in these babies. ${ }^{5}$ Associated abnormalities seen on ultrasound imaging, such as the presence of cardiac defects, provide additional diagnostic clues and may indicate a worse prognosis for the fetus. ${ }^{6}$ Delivery should be planned at an obstetrical centre with ready access to a surgical unit. OA is linked with other clinical defects in more than $50 \%$ of babies, notably the VACTERL sequence (vertebral, anorectal, cardiac, tracheooesophageal, renal, and limb defects) and CHARGE associations (coloboma, heart defects, atresia choanae, retarded development, genital hypoplasia, ear abnormalities) with chromosomal anomalies-that is, trisomy 18 and 21 and DiGeorge syndrome. An increased incidence of associated anomalies is encountered in isolated pure OA $(65 \%) .^{7}$ The risk of recurrence in subsequent pregnancies of non-syndromal OATOF is $<1 \%$. $^{7}$ Parents should therefore not be discouraged from having future children. Familial associations-for example, Feingold syndrome-occur, although they are very rare. ${ }^{8}$

In a seminal paper, David Waterston in 1962 stratified "risk" criteria based on birth weight, pneumonia, and associated anomalies. ${ }^{9}$ Lewis Spitz and colleagues ${ }^{4}$ later proposed a new and simpler system based on associated congenital heart defects and low birthweight status for the modern era. Survival in babies $>1500 \mathrm{~g}$ and without a major cardiac lesion now approaches $97 \%$ (group I), but falls dramatically to only $22 \%$ (group III) if low birth weight $(<1500 \mathrm{~g})$ and a severe heart anomaly coexist. ${ }^{4}$ Other studies from large centres confirm these findings. ${ }^{10}$ Cardiac and chromosomal defects account for most (if not all) early deaths. Ongoing respiratory complications account for late mortality. ${ }^{11}$

\section{BASIC SCIENCE: CONTRIBUTIONS FROM DEVELOPMENTAL BIOLOGY}

The developmental events involved in the separation of the primitive trachea and oesophagus are not fully understood. Several mechanisms are proposed. A widely accepted hypothesis suggests that the trachea and oesophagus develop from a common primitive foregut, and from 4 weeks of gestation the developing respiratory and digestive tubes are separated by lateral ingrowth of epithelial ridges. Defects of mesenchymal proliferation during this critical process have been implicated in the pathoembryogenesis of OA-TOF. The adriamycin rodent model developed by Diez-Pardo and colleagues from Madrid ${ }^{12}$ have furthered our

Abbreviations: OA, oesophageal atresia; TOF, tracheooesophageal fistula 
knowledge in this field along with other research groups interested in the VACTERL sequence. ${ }^{13}{ }^{14}$

At a molecular level, the Sonic hedgehog (Shh) gene is implicated in vertebrate axial organogenesis, which appears essential to foregut development and differentiation. Ioannides et al $^{15}$ noted a reversal in the dorsoventral pattern of Shh expression during the tracheo-oesophageal separation stage in the adriamycin model. In mice with targeted Shh deletion, OA-TOF develops. ${ }^{16}$ Defects in the Shh signalling pathway linked to mutations in Gli2, Gli3 zinc transcription factors result in the VACTERL phenotype..$^{17} 18$

\section{SURGICAL MANAGEMENT OF OA-TOF ANATOMICAL VARIANTS \\ OA-TOF (common variant anomaly)}

Operative repair of OA-TOF follows well established surgical techniques. A right posterolateral (extrapleural) thoracotomy is performed, the fistula ligated, and primary oesophageal anastomosis created. Preoperative echocardiac evaluation is essential, as a right sided aortic arch (2.5\% of cases) signifies a challenging repair best performed via a left thoracotomy. ${ }^{19}$ Morbidity is high for this patient population. The surgeon will encounter circumstances when a primary anastomosis cannot be achieved adequately because of a "long gap" (more than two vertebral bodies) separating the disconnected upper and lower oesophageal segments. Various options-for example, Livaditis myotomy, extensive mobilisation of the distal segment to the diaphragmatic hiatus, and the Foker technique-are available to manage these difficult cases. A high leak rate, oesophageal stricture, and gastro-oesophageal reflux are expected where the anastomosis is created under tension. $^{20}$

Almost 60 years after the first successful primary repair, another landmark in the management of OA was achieved by Tom Lobe and Steve Rothenberg from North America when they undertook the first minimally invasive thoracoscopic repair of OA-TOF. ${ }^{21}$ This was soon followed by successful reports from Bax and van Der Zee ${ }^{22}$ from the Netherlands and G A MacKinlay in Edinburgh (personal communication). Although aesthetically superior to open thoracotomy, minimally invasive techniques do not lessen the potential for stricture and anastomotic leak. Currently this approach should only be offered by advanced paediatric endosurgical centres. ${ }^{23} 24$

\section{Pure "isolated OA"}

Immediate surgical management involves formation of a gastrostomy for feeding and regular suctioning of the "blind" upper pouch to protect the airway. Controversy exists on definitive management. Options for reconstruction include delayed primary repair using the native oesophagus or replacement using isolated colon or stomach (gastric tube or transposition). Preserving the "native" oesophagus is the ideal option, as replacement procedures, although providing an effective conduit for feeding, are linked with high morbidity from recurrent aspiration and chronic respiratory sequelae. Many paediatric surgeons believe that the oesophagus "grows", and, with maturation, a delayed primary anastomosis can be achieved..$^{25}$ A variety of manoeuvres have been described to aid "stretching" of the oesophageal segments. These include bougeinage, electromagnetic stimulation, and graded tension applied to the disconnected oesophageal segments using traction sutures, the Foker technique. ${ }^{26}$ The success of these techniques in retaining the native oesophagus remains unproven.

\section{H-type fistula: a rare variant}

H-type fistulae are usually detected later in infancy or childhood as there is no discontinuity of the oesophagus, and the child is able to feed. Such patients often present with unexplained respiratory symptoms related to aspiration pneumonitis, such as recurrent cough with feeds or "chest infections". Diagnosis can be confirmed by a dynamic prone video oesophagogram. Operation is performed by a neck dissection to expose the anomaly where the fistula is divided and repaired. The operation carries risks of recurrent laryngeal nerve injury, and novel strategies to more accurately identify the fistula at surgery may help to reduce operative trauma. ${ }^{27}$ The Nd:YAG laser has also been used for $\mathrm{H}$ fistula repair, but experience is limited and it is not widely recommended. ${ }^{28}$ Thoracoscopic techniques have been reported for rarer $\mathrm{H}$-type fistulae in the chest. ${ }^{29}$

\section{LONG TERM OUTCOME}

Improved survival for patients with OA has led to a greater appreciation of long term morbidity. Inherent structural and functional defects in the trachea and oesophagus produce significant respiratory and gastro-oesophageal sequelae. ${ }^{30} 31$

\section{Growth and nutrition}

Children with OA tend to have considerable problems with their growth. Poor in utero development has been noted, with almost one third having birth weights $<5$ th centile. ${ }^{32}$ Little et $a^{33}$ further reported that nearly $50 \%$ of children had weights $<25$ th centile during the first crucial 5 years of life. This could be attributed to significant respiratory and gastrointestinal morbidity in the early formative years. Thankfully "catch up" growth occurs, and long term nutritional outcomes are generally excellent, with most survivors attaining reasonable weight as adults. ${ }^{34}$

Feeding problems are a major source of concern in early childhood. A subgroup of patients have aversive feeding behaviour with refusal to eat by the normal oral route. This is due to gastro-oesophageal reflux, anastomotic strictures, and/ or oesophageal dysmotility. A proportion of these children need temporary gastrostomy for aggressive nutritional management. Feeding aversion is more pronounced in those with pure OA, who are exclusively gastrostomy fed in the first few months of life with little oromotor stimulation. Skilled nursing care and input from dieticians is invaluable.

\section{Respiratory system}

Respiratory problems are common in children with OA and TOF. Severe tracheomalacia and bronchomalacia occur in 10$20 \%$ of infants. Airway instability and collapse can be severe enough to cause life threatening obstruction. ${ }^{35}$ A minority of infants will require aortopexy to stabilise the trachea and permit weaning from mechanical ventilation. Many children have a characteristic harsh barking "TOF cough" which is a manifestation of tracheomalacia. Recurrent chest infections-bronchitis and pneumonia-occur in up to two thirds of TOF survivors in the early years of life. ${ }^{36}$ Repeated infections or aspiration may lead to irreversible lung damage with bronchiectasis and persistent lobar collapse. Wheeze occurs in $40 \%$ of survivors, and tends not to improve with age.

Many factors contribute to recurrent respiratory symptoms. The epithelium in the major airways is abnormal, which impairs mucociliary clearance of secretions, an important defence mechanism for the respiratory tract. There is also a clear link between severity of gastro-oesophageal reflux and the persistence of symptoms. Strictures and impaired peristalsis (dysmotility) leads to food debris accumulating in the upper third of the oesophagus with overspill into the trachea causing recurrent aspiration episodes. Rarely persistence or worsening of symptoms may be due to a recurrent TOF.

Respiratory morbidity decreases in frequency and severity as the child reaches late adolescence. ${ }^{36}$ Abnormalities of 
pulmonary function, include airflow limitation, reduced lung volumes, and hyperinflation in up to $40 \%$ of survivors. These are unlikely to restrict normal childhood activities. ${ }^{37-39}$

Management includes tailored use of antibiotics, physiotherapy, and optimal management of gastro-oesophageal reflux to minimise the risk of recurrent aspiration. Antiasthma treatments such as inhaled bronchodilators and inhaled steroids prove useful. Chest imaging-plain radiographs and computed tomography scans-together with serial lung function tests are invaluable in monitoring progress.

\section{Gastro-oesophageal morbidity}

Strictures at the anastomotic site are an early complication requiring dilatation in nearly half of all patients. ${ }^{40}$ Prophylactic dilatation does not confer benefit. ${ }^{41}$ Most surgeons currently offer dilatation based on symptoms only. A minority will require resection of the stricture segment. Gastro-oesophageal reflux can significantly increase the risk of stricture formation, and fundoplication may ameliorate recalcitrant strictures.

Gastro-oesophageal reflux is recorded in almost $50 \%$ of children, although it is universally present to a degree in all patients. ${ }^{42}$ This can lead to oesophagitis, stricture(s), nutritional and respiratory problems. It is advisable to start all patients on antireflux medical treatments (including feed thickeners, $\mathrm{H}_{2}$ blockers, proton pump inhibitors, and prokinetic drugs) and continue these for at least the 1218 months of life until upright posture is achieved. Reflux will improve, with only one third of children followed into adulthood experiencing continued symptoms. Antireflux surgery is reserved for troublesome symptoms. ${ }^{42}$ Barrett's oesophagus (metaplasia) has been reported in $6-8 \%$ of cases. $^{43}$ This supports a vigilant policy of long term surveillance, as oesophageal carcinoma has been encountered in adults. ${ }^{44}$

Oesophageal dysmotility is an expected finding and can be shown on manometry in $75-100 \%$ of children after operative primary repair. ${ }^{43}$ Disorganised propulsive activity with ineffective clearance of gastric acid is noted. Likewise, most patients who have undergone oesophageal replacement will also experience "foregut" problems with the conduit (colon or stomach). These include episodes of aspiration, dysphagia, food bolus obstruction, failure to thrive, or "choking" spells. ${ }^{43}{ }^{45}$ Children and adults learn to adapt with modifications to the diet, such as avoiding certain foods and drinking frequently when they eat.

\section{Musculoskeletal system}

Open thoracotomy can lead to significant musculoskeletal morbidity. Associated vertebral defects as part of the VACTERL sequence can contribute to deformities of the spine or chest wall. One report noted that $24 \%$ of patients had a "winged" scapula secondary to partial paralysis of the lattissimus dorsi muscle, with $20 \%$ of children having chest wall asymmetry because of atrophy of the serratus anterior. ${ }^{46}$ Other sequelae include fusion of ribs and, in the female breast, asymmetry with disfigurement. ${ }^{46}{ }^{47}$ Modified axillary incisions as described by Bianchi et al ${ }^{48}$ or thoracoscopy techniques provide attractive solutions to further reduce morbidity.

\section{Quality of life}

Adults with OA after successful primary anastomosis have been shown to enjoy an unimpaired quality of life. ${ }^{49}{ }^{50}$ Quality of life as assessed by the Spitzer index and gastrointestinal quality of life index score appear significantly worse in patients who have had colon interposition replacement than in those who have had native primary repair. ${ }^{49}$ Further clinical outcome based studies are needed.
The UK based tracheo-oesophageal fistula support group was established in 1982 to help affected parents, families, and children with OA adapt to the ongoing challenges. ${ }^{51-53}$ Similar networks exist in other countries-for example, KEKS in Germany. Increasing public awareness and promoting research for the birth defect are valuable benefits of this energetic organisation. ${ }^{545}$

\section{FUTURE DIRECTIONS}

Although research in the basic sciences has given new insight into the biology of foregut development, translational benefits have yet to be achieved. In centres striving to offer "world class care", the emergence of TOF clinics coordinated by multidisciplinary teams (surgeons, respiratory physicians, physiotherapy, dieticians, and speech therapists) has greatly improved the management of these complex children. The challenge for the future is to further reduce morbidity to enable survivors and families lead normal productive lives in society.

\section{Authors' affiliations}

A Goyal, M O Jones, J M Couriel, P D Losty, Departments of Paediatric Surgery and Paediatric Respiratory Medicine, Royal Liverpool Children's Hospital (Alder Hey), and Department of Child Health, University of Liverpool, UK

Competing interests: none declared

\section{REFERENCES}

1 Haight C, Towsley HA. Congenital atresia of the esophagus with tracheoesophageal fistula: extrapleural ligation of fistula and end to end anastomosis of esophageal ends. Surg Gynecol Obstet 1943;76:672-88.

2 Spitz L. Esophageal atresia: past, present, and future. J Pediatr Surg 1996:31:19-25.

3 Konkin DE, O'Hali WA, Webber EM, et al. Outcomes in esophageal atresia and tracheoesophageal fistula. J Pediatr Surg 2003;38:1726-9.

4 Spitz L, Kiely EM, Morecroft JA, et al. Oesophageal atresia: at-risk groups for the 1990's. J Pediatr Surg 1994;29:723-5.

5 Stringer MD, McKenna KM, Goldstein RB, et al. Prenatal diagnosis of esophageal atresia. J Pediatr Surg 1995;30:1258-63.

6 Sparey C, Jawaheer G, Barrett AM, et al. Esophageal atresia in the Northern Region Congenital Anomaly Survey, 1985-1997: prenatal diagnosis and outcome. Am J Obstet Gynecol 2000;182:427-31.

7 Spitz L. Esophageal atresia and tracheo-esophageal malformations. In: Ashcraft KW, Holcomb GW, Murphy JP, eds. Pediatric surgery.4th ed. Amsterdam: Elsevier Saunders, 2005:352-70.

8 Feingold M, Hall BD, LacassieY, et al: Syndrome of microcephaly, facial and hand abnormalities, tracheo-esophageal fistula, duodenal atresia, and developmental delay. Am J Med Genet 1997;69:245-9.

9 Waterston DJ, Carter Re, Aberdeen E. Oesophageal atresia: tracheooesophageal fistula. A study of survival in 218 infants. Lancet 1962;21:819-22.

10 Driver $\mathrm{CP}$, Shankar KR, Jones $\mathrm{MO}$, et al. Phenotypic presentation and outcome of esophageal atresia in the era of the Spitz classification. J Pediatr Surg 2001;36:1419-21.

11 Choudhury SR, Ashcraft KW, Sharp RJ, et al. Survival of patients with esophageal atresia: influence of birth weight, cardiac anomaly, and late respiratory complications. J Pediatr Surg. 1999;34: 70-3; discussion 74).

12 Diez-Pardo JA, Baoquan Q, Navarro C, et al. A new rodent experimental model of esophageal atresia and tracheoesophageal fistula: preliminary report. J Pediatr Surg 1996;31:498-502.

13 Gillick J, Mooney E, Giles S, et al. Notochord anomalies in the adriamycin rat model: A morphologic and molecular basis for the VACTERL association. J Pediatr Surg 2003;38:469-73.

14 Merei J, Hasthorpe S, Farmer P, et al. Relationship between esophageal atresia with tracheoesophageal fistula and vertebral anomalies in mammalian embryos. J Pediatr Surg 1998;33:58-63.

15 loannides AS, Henderson DJ, Spitz L, et al. Role of Sonic hedgehog in the development of the trachea and oesophagus. J Pediatr Surg 2003;38:29-3629.

16 Litingtung $Y$, Lei L, Westphal $H$, et al. Sonic hedgehog is essential to foregut development. Nat Genet 1998;20:58-61

17 Kim PC, Mo R, Hui CC. Murine models of VACTERL syndrome: role of sonic hedgehog signaling pathway. J Pediatr Surg 2001;36:381-4.

18 Spilde T, Bhatia A, Ostlie D, et al. A role for sonic hedgehog signaling in the pathogenesis of human tracheoesophageal fistula. J Pediatr Surg 2003;38:465-8.

19 Babu R, Pierro A, Spitz L, et al. The management of oesophageal atresia in neonates with right-sided aortic arch. J Pediatr Surg 2000;35:56-8. 
20 Hagberg S, Rubenson A, Sillen U, et al. Management of long-gap esophagus: experience with end-to-end anastomosis under maximal tension. Prog Pediatr Surg 1986;19:88-92.

21 Lobe TE, Rothenberg SS, Waldschmidt J, et al. Thoracoscopic repair of esophageal atresia in an infant: A surgical first. Pediatric Endosurgery Innovative Techniques 1999;3:141-8.

22 Bax KM, van Der Zee DC. Feasibility of thoracoscopic repair of esophageal atresia with distal fistula. J Pediatr Surg 2002;37:192-6.

23 Rothenberg SS. Thoracoscopic repair of esophageal atresia and tracheoesophageal fistula. Semin Pediatr Surg 2005;14:2-7

24 Jaffray B. Minimally invasive surgery. Arch Dis Child 2005;90:537-42.

25 Puri P, Ninan GK, Blake NS, et al. Delayed primary anastomosis for esophageal atresia: 18 months' to 11 years' follow-up. J Pediatr Surg 1992;27:1 127-30.

26 Foker JE, Kendall TC, Catton K, et al. A flexible approach to achieve a true primary repair for all infants with esophageal atresia. Semin Pediatr Surg 2005; 14:8-15.

27 Goyal A, Potter F, Losty PD. Transillumination of H-type tracheoesophageal fistula using flexible miniature bronchoscopy: an innovative technique for operative localization . J Pediatr Surg 2005;40:e33-4.

28 Bhatnagar V, Lal R, Sriniwas $M$, et al. Endoscopic treatment of tracheoesophageal fistula using electrocautery and the Nd:YAG laser. $J$ Pediatr Surg 1999;34:464-7.

29 Allal H, Montes-Tapia F, Andina G, et al. Thoracoscopic repair of H-type tracheoesophageal fistula in the newborn: a technical case report. J Pediatr Surg 2004;39:1568-70.

30 Emery JL, Haddadin AJ. Squamous epithelium in respiratory tract of children with tracheo-oesophageal fistula. Arch Dis Child 1971;46:236-42.

31 Dutta HK, Mathur M, Bhatnagar V. A histopathological study of esophageal atresia and tracheoesophageal fistula. J Pediatr Surg 2000;35:438-41.

32 David TJ, O'Callaghan SE. Oesophageal atresia in the South West of England. J Med Genet 1975;12:1-11.

33 Little DC, Rescorla FJ, Grosfeld JL, et al. Long-term analysis of children with esophageal atresia and tracheoesophageal fistula. J Pediatr Surg 2003:38:852-6.

34 Chetcuti P, Phelan PD. Gastrointestinal morbidity and growth after repair of oesophageal atresia and tracheo-oesophageal fistula. Arch Dis Child 1993;68:163-6.

35 Spitz L. Esophageal atresia and tracheoesophageal fistula in children. Curr Opin Pediatr 1993;5:347-52.

36 Chetcuti P, Phelan PD. Respiratory morbidity after repair of oesophageal atresia and tracheo-oesophageal fistula. Arch Dis Child 1993;68:167-70.

37 Chetcuti P, Phelan PD, Greenwood R. Lung function abnormalities in repaired oesophageal atresia and tracheo-oesophageal fistula. Thorax 1992;47:1030-4
38 Couriel JM, Hibbert M, Olinsky A, et al. Long term pulmonary consequences of oesophageal atresia with tracheo-oesophageal fistula. Acta Paediatr Scand 1982;71:973-8

39 Robertson DF, Mobaireek K, Davis GM, et al. Late pulmonary function following repair of tracheoesophageal fistula or esophageal atresia. Pediatr Pulmonol 1995;20:21-6.

40 Nambirajan L, Rintala RJ, Losty PD, et al. The value of early postoperative oesophagography following repair of oesophageal atresia. Pediatr Surg Int 1998:13:76-8

41 Koivusalo A, Turunen P, Rintala RJ, et al. Is routine dilatation after repair of esophageal atresia with distal fistula better than dilatation when symptoms arise? Comparison of results of two European pediatric surgical centers. J Pediatr Surg 2004;39:1643-7.

42 Engum SA, Grosfeld JL, West KW, et al. Analysis of morbidity and mortality in 227 cases of esophageal atresia and/or tracheoesophageal fistula over two decades. Arch Surg 1995;130:502-8.

43 Somppi E, Tammela O, Ruuska T, et al. Outcome of patients operated on for esophageal atresia: 30 years' experience. J Pediatr Surg 1998;33:1341-6.

44 Adzick NS, Fisher JH, Winter HS, et al. Esophageal adenocarcinoma 20 years after esophageal atresia repair. J Pediatr Surg 1989;24:741-4.

45 LeSouef PN, Myers NA, Landau LI. Etiologic factors in long-term respiratory function abnormalities following esophageal atresia repair. J Pediatr Surg 1987;22:918-22.

46 Jaureguizar E, Vazquez J, Murcia J, et al. Morbid musculoskeletal sequelae of thoracotomy for tracheoesophageal fistula. J Pediatr Surg 1985;20:511-14.

47 Cherup LL, Siewers RD, Futrell JW. Breast and pectoral muscle maldevelopment after anterolateral and posterolateral thoracotomies in children. Ann Thorac Surg 1986;41:492-7.

48 Bianchi A, Sowande O, Alizai NK, et al. Aesthetics and lateral thoracotomy in the neonate. J Pediatr Surg 1998;33:1798-800

49 Ure BM, Slany E, Eypasch EP, et al. Quality of life more than 20 years after repair of esophageal atresia. J Pediatr Surg 1998:33:511-15.

50 Koivusalo A, Pakarinen MP, Turunen P, et al. Health-related quality of life in adult patients with esophageal atresia: a questionnaire study. J Pediatr Surg 2005;40:307-12.

51 Martin V. The TOF child, 1st ed. Nottingham: Blueprint Group (UK) Ltd).

52 Puntis JW, Ritson DG, Holden CE, et al. Growth and feeding problems after repair of oesophageal atresia. Arch Dis Child 1990;65:84-8.

53 Chetcuti P, Myers NA, Phelan PD, et al. Adults who survived repair of congenital oesophageal atresia and tracheo-oesophageal fistula. $B M$ 1988;297:344-6.

54 Schier F, Korn S, Michel E. Experiences of a parent support group with the long-term consequences of esophageal atresia. J Pediatr Surg 2001;36:605-10.

55 Losty PD, Baillie CT. Esophageal atresia and tracheo-esophageal atresia. In: Puri P, eds. Newborn surgery.2nd ed. London: Edward Arnold 2003:337-52. 